\title{
Observations on the variability and screening effect of Sporadic-E
}

\author{
S.E. Ritchie ${ }^{\mathrm{a}, \mathrm{b}, *}$, F. Honary ${ }^{\mathrm{b}}$ \\ a Commission for Communications Regulation (ComReg), Irish Life Centre, Lower Abbey Street, Dublin 2, Ireland \\ ${ }^{\mathrm{b}}$ Department of Communication Systems, University of Lancaster, Lancaster LA1 4W4, UK
}

\section{A R T I C L E I N F O}

\section{Article history:}

Received 30 June 2008

Received in revised form

5 May 2009

Accepted 16 May 2009

Available online 28 May 2009

Keywords:

Sporadic-E

SSC

High latitude

\begin{abstract}
A B S T R A C T
Sporadic-E is a problem in high latitude HF communications because of its irregular and as yet unpredictable behaviour. This paper characterises the change in E-layer critical frequency $\left(f_{\mathrm{o}} E\right)$ that occurs in the four hours following a storm sudden commencement (SSC) event which is a precursor to magnetospheric storms which adversely affect ionospheric communications.

Following checks for any seasonal or solar activity dependency in the data, further analysis determines the occurrence of full blanketing (screening) Sporadic-E layer formation at high latitudes as seen on vertical ionosondes in Northern Finland (67 $7^{\circ}$ Latitude). An appropriate threshold value of $f_{\mathrm{o}} E$ is proposed that could be used following the commencement of ionospheric storms, indicating that there is a high probability that F-layer screening will occur. As far as the authors are aware this is the first statistical analysis of the onset of Sporadic-E following SSC.
\end{abstract}

(c) 2009 Elsevier Ltd. All rights reserved.

\section{Introduction}

A significant problem in using any F-layer propagation mode at high latitudes is the large variability of this layer on the time scale of fractions of an hour in these regions. The $\mathrm{F}_{2}$-layer is known to have significant variability at mid-latitudes, often exhibiting variations of $1-2 \mathrm{MHz}$ in the MUF(3000) over less than $1 \mathrm{~h}$ (Paul, 1985). Although data on MUF(3000) variability at high latitudes is scarce, there are reasons to believe that the temporal variability for this mode would be considerably greater at high latitudes than at mid-latitudes.

One of the most detrimental effects of Sporadic-E $\left(E_{s}\right)$ on HF propagation is the screening effect which occurs due to the sudden occurrence of an intense $E_{s}$ layer which prevents any signal from penetrating the E-region and reaching the F-layer. Firstly this paper examines the variability that occurs in the E-layer, which causes significant deviations from expected median values as calculated by propagation prediction algorithms. Secondly this paper determines, by observation, an appropriate threshold value of $f_{\mathrm{o}} E$ that indicates the onset of screening.

$E_{s}$ is defined as an altitude-thin E-region layer at an unpredictable altitude and/or an unexpected intensity (Mathews, 1998). Historically the term "Sporadic-E" derives from ionosonde observations and from the beginning has been used to describe a variety of E-region echoes from a variety of HF sounding

\footnotetext{
* Corresponding author at: Commission for Communications Regulation (ComReg), Irish Life Centre, Lower Abbey Street, Dublin 2, Ireland. Tel.: +35318049619.

E-mail addresses: samuel.ritchie@comreg.ie (S.E. Ritchie) f.honary@lancaster.ac.uk (F. Honary).
}

instruments. The term "sporadic" continues to pose semantic difficulties in that the different classifications of $E_{s}$ display various levels of periodicity and thus predictability. The most common current definition of $E_{s}$ is simply that of an ionisation layer lying anywhere in the E-region.

In discussing Sporadic-E we must be very careful in the terminology used. In the literature the phrase "Sporadic-E" is applied to different types of layers that form around the $100 \mathrm{~km}$ altitude mark. For example, the evening $\mathrm{E}_{\mathrm{s}}$ and midnight $\mathrm{E}_{\mathrm{s}}$ are not the intense, often blanketing E-layers dealt with in this report. Both of these types of $E_{s}$ are thin layers and understood to be caused by vertical wind shears and ionospheric electric fields (Wan et al., 1999).

\subsection{Causes of $E_{s}$}

$\mathrm{E}_{\mathrm{s}}$ arises when clouds of intense ionisation occasionally form in the E-region ionosphere. The most common theoretical explanation of the formation of Sporadic-E layers in low- and midlatitudes is the wind shear theory (e.g., Whitehead, 1961; Mathews, 1998). According to this theory, ions are accumulated into thin, patchy sheets by the action of high-altitude winds in the E-region ionosphere. Wind shear occurs at the boundary between two wind currents of different speed, direction, or both. For example, two high-speed winds blowing approximately in opposite directions in the E-region ionosphere create a wind shear, which makes it possible to redistribute and compress ionised particles into a thin layer.

It has also been suggested that the electric field alone can produce $E_{s}$ layers (Nygréen et al., 1984). This theory demands an 
electric field pointing in a proper direction. Convincing evidence for the electric field theory has been presented by Parkinson et al. (1998) who presented the number of observed $E_{s}$ layers versus electric field direction at Antarctica and confirmed that this theory is particularly effective at high latitudes where strong electric fields are encountered. This theory leads to compressive vertical plasma flow if the ionosphere electric field points in some direction between west and north in the northern hemisphere and between west and south in the southern hemisphere. In their detailed review, Kirkwood and Nilsson (2000) examined different high latitude thin layers comparing the wind shear and electric field theories of layer formation, noting that a number of important questions remain unanswered.

More recently, Damatie et al. (2002) found evidence for the presence of vertical shears in the meridional E-region neutral wind as well as the right conditions for the electric field theory. Using data from the SuperDARN radars they detected the presence of an ionospheric electric field pointing in the sector between west and north. The conclusion is that both mechanisms may be active simultaneously and that their relative importance remains unknown.

King (1962) inclines to the view that the ionisation moves down from the F-region, however as the ionisation has to be replaced at least every few hundred seconds (with the lowest recombination coefficient acceptable) the whole of the F-region ionisation would be depleted in a few hours.

Whitehead (1970) suggested a three-stage phenomenon. First of all, we have ionisation by incoming particles. The dumping mechanism may itself be associated with magnetic activity. Sufficient ionisation may be produced to give a plasma frequency approaching $2 \mathrm{MHz}$ in a thick layer. A second mechanism forms this ionisation into irregularities with a plasma frequency approaching $10 \mathrm{MHz}$ (to account for the $f_{\mathrm{o}} E_{\mathrm{s}}$ observed on ionograms), and possibly the same mechanism or a third one causes the smaller irregularities for the VHF reflections.

The influence of geomagnetic disturbances on $E_{s}$ layers in general has been investigated by a number of researchers (Whitehead, 1970, 1989; Majeed, 1982; Baggaley, 1984), where both positive and negative correlations of $\mathrm{E}_{\mathrm{s}}$ with the geomagnetic activity as well as the absence of correlation were revealed. They also reported on the dependence of the $E_{s}$ layer response to the geomagnetic disturbances on latitude, season, time of the day and the type of $E_{s}$ layer. It appears that the question of the influence and prediction of geomagnetic disturbances on the $E_{s}$ layer has not yet been solved completely.

Maksyutin et al. (2001) performed an analysis of dependence of $E_{s}$ layer response to geomagnetic disturbances on the level of solar activity and showed that during the years with a low level of solar activity, the $\mathrm{E}_{\mathrm{s}}$ layer response to the geomagnetic disturbances was more pronounced than during the years with a high level of solar activity.

High latitude $\mathrm{E}_{\mathrm{s}}$ layers are generally considered to be due to particle precipitation (Buchau et al., 1972; Whitehead, 1970; Whalen et al., 1971; Wagner et al., 1973). Naridner et al. (1980) found that electron precipitation usually is the major cause for the formation of the high latitude Sporadic-E layer and that the modified wind shear mechanism, which takes into account the effect of electric fields, is important under low electron precipitation conditions only.

At high latitudes most of the time the ionisation is dominated by energetic charged particles (electrons or protons) and only rarely is the ionosphere "quiet", i.e. it varies with solar zenith angle and solar activity (Friedrich, 2002). It is acknowledged that at high latitudes the sun is able to produce an $\mathrm{E}$ layer when it is above the horizon. However, ionisation can also be produced in the same altitude range by the precipitation of energetic particles, principally electrons which then dominate and control the characteristics of the E-layer. For example, in the course of a substorm, precipitation of charged particles from the magnetosphere into the ionosphere takes place, the electrojet is increased, the substorm current wedge system is formed and the electron density and composition of the ionosphere are changed (Buonsanto, 1999). It is known that during the substorm growth phase, accelerated particles from the solar wind can penetrate through the entry layer of the magnetosphere into the auroral ionosphere (Blagoveshchensky and Borisova, 2000), often causing intense $\mathrm{E}_{\mathrm{s}}$ layers.

\subsection{Storm sudden commencement-the link to $E_{s}$}

An interplanetary disturbance in the solar wind such as shock waves and dynamic pressure pulses (Wilken et al., 1982; Tsurutani et al., 1995; Takeuchi et al., 2002), when impinging on the Earth's magnetosphere, compresses it and increases the magnetopause current. This leads to a change in the low-latitude ground-based geomagnetic field intensity, lasting typically for some tens of minutes. These signatures in the geomagnetic H-field, seen suddenly and simultaneously at ground magnetic observatories (Rastogi et al., 2001), are called storm sudden commencements (SSC) or sudden impulses (SI), depending on whether a magnetospheric storm is initiated or not.

The International Association of Geomagnetism and Aeronomy (IAGA) collates widespread observatory magnetometer data in order to compile a list of agreed SSC events (Ebro, 2009). Burlaga and Ogilvie (1969), Gosling et al. (1967) and Ogilvie et al. (1968) have shown the good correlation between these impulsive changes in solar wind parameters and SSC signatures in the magnetosphere or on the ground. The same researchers as well as Hirshberg et al. (1970) demonstrated that SCC events are caused by hydromagnetic shock waves and tangential discontinuities in the solar wind interacting with the magnetosphere. The SSC generated by these hydromagnetic shock waves transform the magnetosphere into a new compressed steady state configuration, which is in balance with the increased solar wind pressure (Wilken et al., 1982, 1986; Tamao, 1964, 1975).

Collis and Haggstrom (1991) studied the response of the high latitude ionosphere to an SSC. Their results show that an increase in E-region electron density at the time of the SSC is not caused by an influx of ionisation from higher altitude layers and is not due to a sudden inflow of ionisation from the equator. The sudden E-region enhancement in this study is therefore more likely due to a sudden and sustained dumping of high-energy particles, as a result of the SSC, causing enhanced $E_{s}$ layer ionisation.

The onset of intense $\mathrm{E}_{\mathrm{s}}$ following an SSC just after midnight and lasting up to $12 \mathrm{~h}$ has been noted by Herman and Penndorf (1963). In this particular case $f_{\mathrm{o}} E$ reached $12 \mathrm{MHz}$ and the $\mathrm{E}_{\mathrm{s}}$ layer covered most of North America above $40^{\circ} \mathrm{N}$ within two hours of the SSC. Other observations (Batista et al., 1991; Morton and Mathews, 1993) have also shown that during large geomagnetic storms, the electron density of the lower ionosphere increased significantly compared to quiet conditions.

\section{Data gathering}

The data used in this report are gathered from f-plots generated at the Sodankylä observatory, which is located $120 \mathrm{~km}$ north of the Arctic Circle in Finland, $67^{\circ} 22^{\prime} \mathrm{N}, 26^{\circ} 38^{\prime} \mathrm{E}, L$-value 5.2. Data for this research work were gathered over six years from the sunspot minimum in 2000 until the near sunspot maximum in 2006. 
The daily f-plot reveals on an hourly basis frequency characteristics of a full day's ionograms using an internationally agreed convention, so that detailed observations from different stations may be compared efficiently. The f-plot provides a summary of the original observations with the minimum of interpretation and enables difficult decisions on the true values of ionospheric parameters, needed for hourly tabulations, to be made with due consideration of all the available data. This is particularly important at high latitude stations where blackouts, spread echoes or rapidly changing oblique reflections frequently obscure the normal characteristics from being observed on individual hourly ionogram records. It has been acknowledged that the f-plot is a valuable tool for identifying variations in the ionosphere, in the interpretation of complex records, particularly at high latitudes and it has become a primary tool for analysing the hour-to-hour or day-to-day changes in the ionosphere (Piggott and Rawer, 1972).

The starting point for this study is the occurrence of an SSC, which denotes an increase in low-latitude magnetic intensity, which typically lasts for tens of minutes and then is followed by a magnetic storm or by an increase in geomagnetic activity lasting at least one hour, i.e., a period of ionospheric disturbances and corresponding variability in ionospheric communications. In using the IAGA database of SSC events the occurrence of magnetospheric changes and modifications to the ionosphere (a disturbed state) is guaranteed. This is done in preference to the standard use of the $K_{\mathrm{p}}$ value, which as a three hourly index does not provide the resolution required for this investigation. In order to identify data that capture all the E-layer effects that are initiated with an SSC occurring, data are analysed for the four hours following SSC.

For each of the four hours following an SSC, the following statistics are collected for each sector from the f-plot generated at the Sodankylä observatory. The mean, median, minimum, maximum, lower quartile and upper quartile of the change in critical frequency $\left(\Delta f_{\mathrm{o}} E\right)$ that occur in each sector, the percentage of screening (total blanketing) that occurs in each sector and the critical frequency of the E-layer $\left(f_{\mathrm{o}} E\right)$ at which screening occurs.

The difference in critical frequency measured on each hour following an SSC event is used to define the variability that occurs. This difference is designated in this paper as $\Delta f_{\mathrm{o}} E_{n-m}$ where $\Delta f_{\mathrm{o}} E$ is the change in hourly E-layer critical frequency and $n$ and $m$ indicate which hour following the SSC is being measured. These values reflect the reduction or increase in E-layer ionisation due to all applicable factors. However as enhanced ionisation due to particle precipitation which is by far the dominant ionisation source (see Section 1.1), $\Delta f_{\mathrm{o}} E_{n-m}$ captures predominantly the influence of particle precipitation.

Bearing in mind that the f-plot accumulates hourly data, the critical frequency of the E-layer is noted on the hour before the SSC occurs (called $F_{\mathrm{o}} E_{0}$ ). The same information is then gathered on the hour following the SSC (denoted as $\Delta f_{0} E_{0-1}$ ) and every hour there after for four hours ( $\Delta f_{\mathrm{o}} E_{1-2}$ to $\left.\Delta f_{\mathrm{o}} E_{3-4}\right)$.

\subsection{Discounting solar control}

The E-layer is generally considered to be under the control of solar radiation because in many low-latitude ionograms the E-layer regularly forms as the sunrise reaches $100 \mathrm{~km}$ altitude and begins to fade as sunset falls below $100 \mathrm{~km}$ altitude. There is also a very strong correlation between sunspot number, as a measure of solar activity, and the critical frequency of the E-layer at low- and mid-latitudes (Smith, 1957, 1962). It is easy to see that this assumption has limited applicability at high latitudes in disturbed conditions during which the E-layer is modified extensively by

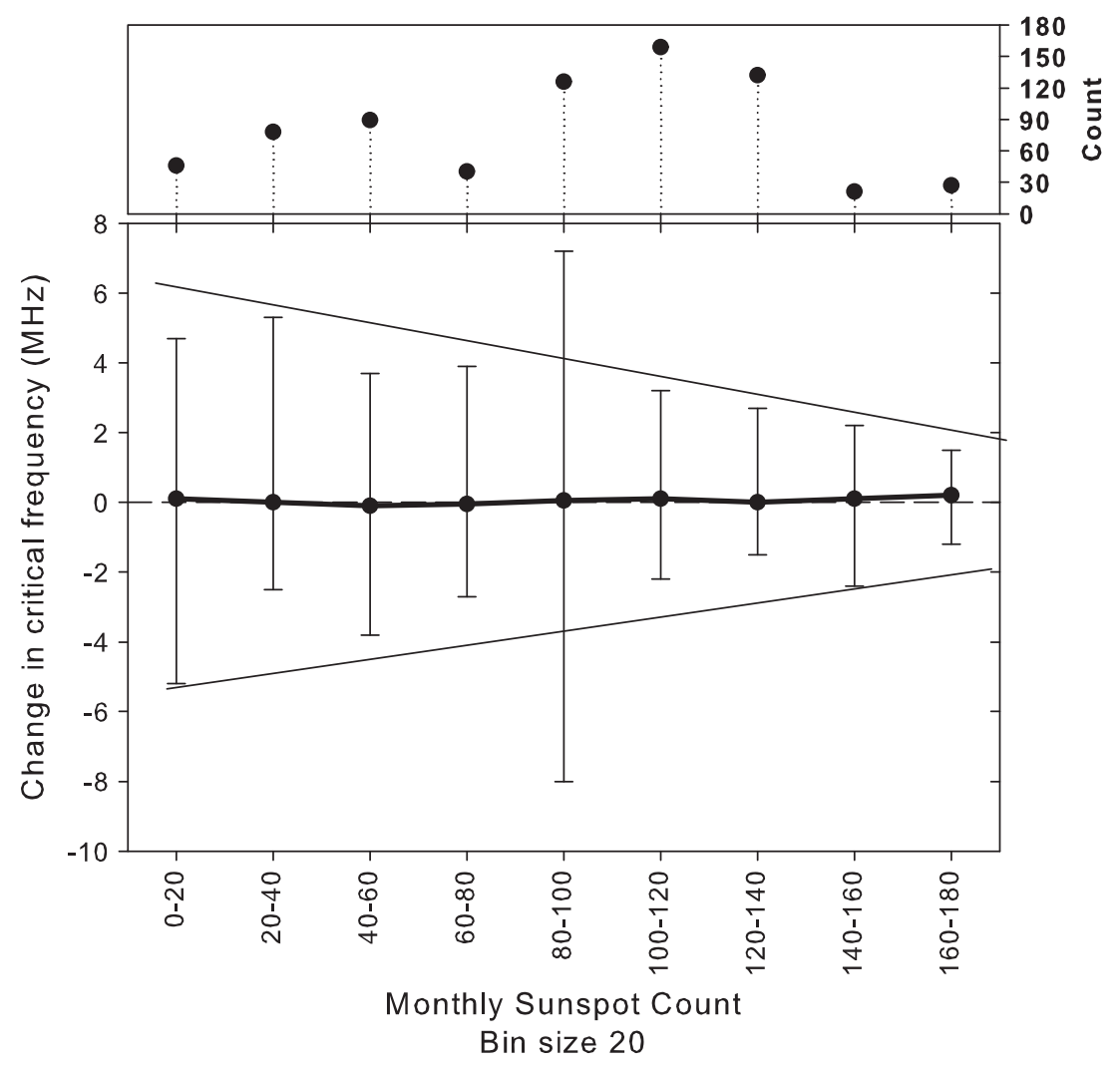

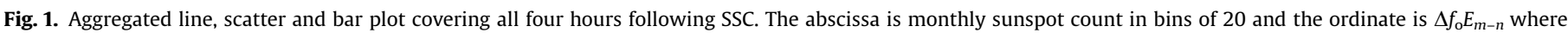
$m-n$ denotes the hour of measurement. 
particle precipitation, which itself has no seasonal variations and is not under the influence of solar activity, other than in the number of disturbances that occur. As shown by Baron (1974) and Hinteregger et al. (1965) the ionisation produced by particle precipitation is two orders of magnitude greater than that produced by photo-ionisation. Intense precipitation is therefore the dominant mechanism affecting the high latitude ionosphere, especially during magnetic disturbances. This removes most if not all solar and seasonal control concerns and reflects the conclusions of a number of researchers, e.g. Hargreaves (1992), McNamara (1991), Davies (1990), etc.

\section{Data analysis}

\subsection{Discounting dependency on solar activity}

We examine first if there is any dependency in the data on solar activity by using the monthly sunspot number as a proxy for solar activity. The line, scatter and error bar plots in the bottom panel of Fig. 1 capture the change in $f_{\mathrm{o}} E$ measured across the first four hours following SSC. The points joined by the solid line are the median value of all $\Delta f_{\mathrm{o}} E$ values that fall within each sunspot number range bin. The error bars show the minimum and
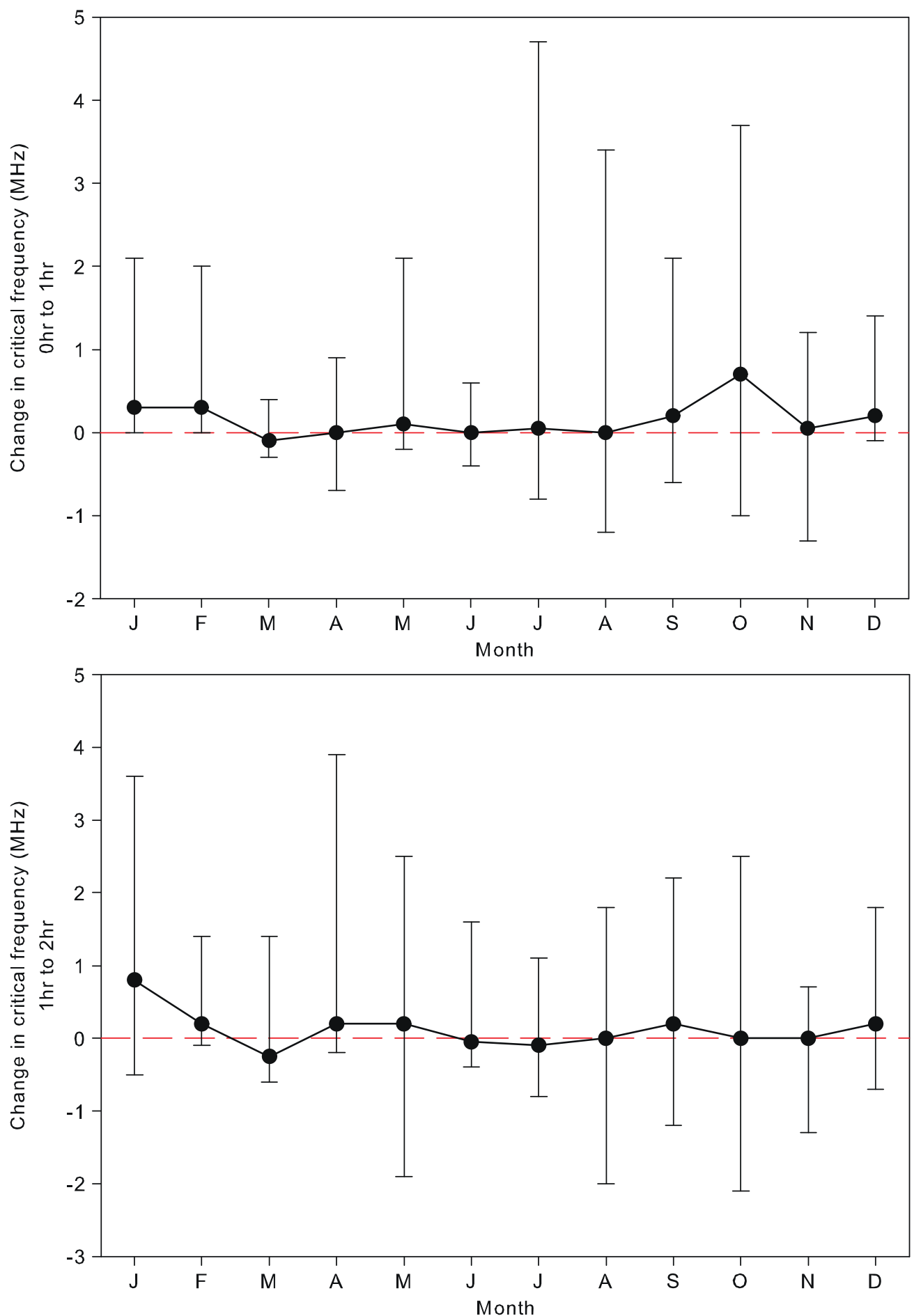

Fig. 2. Line, scatter and bar plots for each hour following SSC. The abscissa is month of measurement and the ordinate is $\Delta f_{\mathrm{o}} E_{m-n}$. 

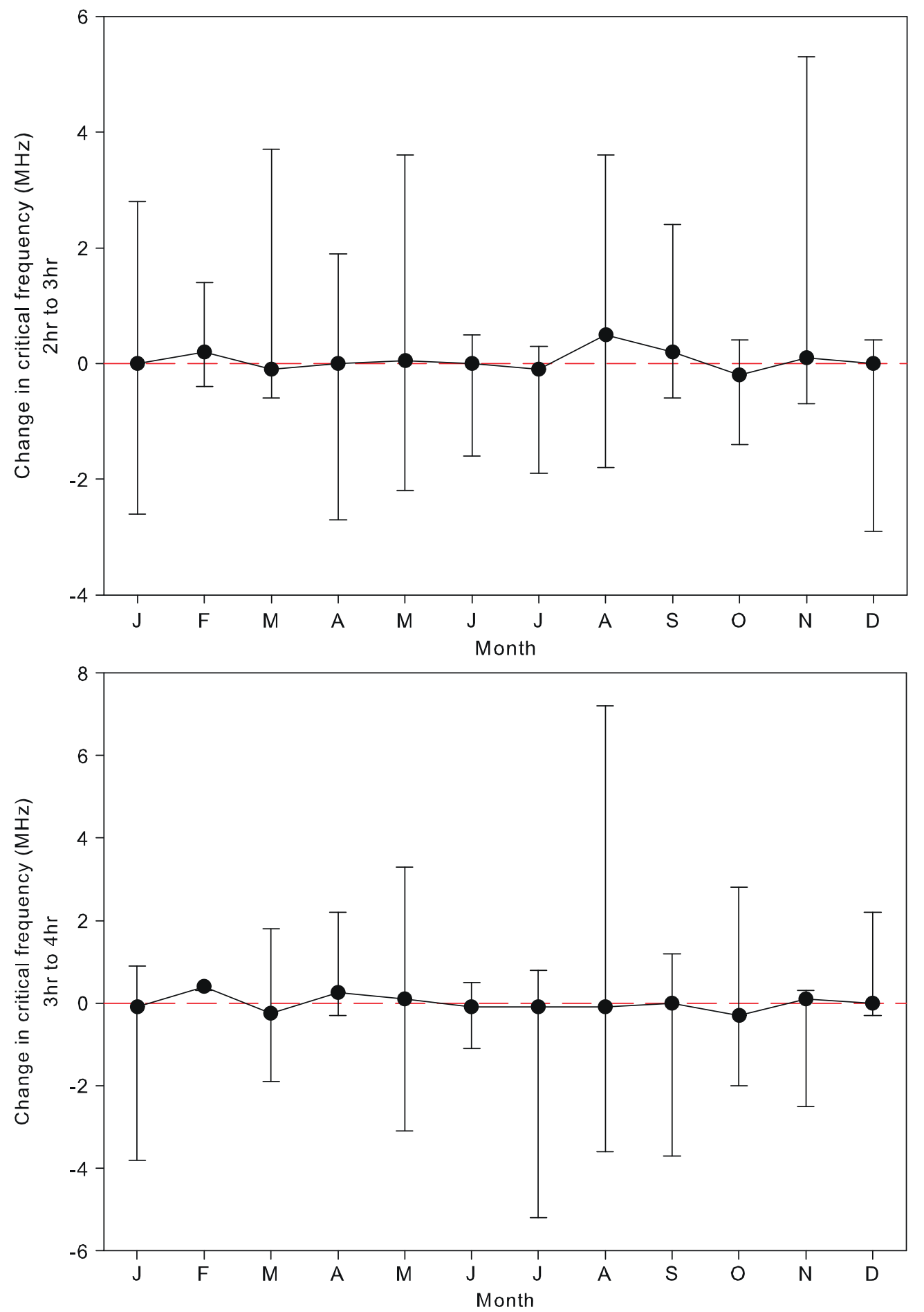

Fig. 2. (Continued)

maximum values for each bin used here in preference to quartile values in order to expose the full magnitude of variability that can be expected. The behaviour of $\Delta f_{\mathrm{o}} E$ across the first four hours is similar to the behaviour of $\Delta f_{\mathrm{o}} E$ when each hour is examined in isolation. The scatter plot with dropped vertical lines in the top panel of Fig. 1 details the number of measurements covered in each bin.

Two general observations are made on the change that occurs in the four hours following an SSC. First is that there is no distinctive pattern of change in the median value of $\Delta f_{\mathrm{o}} E_{m-n}$ as solar activity increases; there is a slight increase when the monthly sunspot number (MSN) exceeds 140 , but this is inconclusive as there is a similar increase at very low MSNs. Second is that there is a reduction in the overall variability of $\Delta f_{\mathrm{o}} E_{m-n}$ as solar activity increases. At high values of MSN greater than 100 , the variability is significantly reduced. The two converging lines in Fig. 1 merely indicate the decreasing trend in overall variability, i.e. a reduction in the variability of $\Delta f_{\mathrm{o}} E_{\mathrm{s}}$ as solar activity increases. Even when discounting the two upper bins with a low count (covering MSC of 140-180), the decrease in 
variability with increasing monthly sunspot count is evident. The reason for this reduction in variability is not clear but it confirms the findings of Maksyutin et al. (2001) who performed an analysis of the dependence of $E_{s}$ layer response to geomagnetic disturbances on the level of solar activity. They showed that during the years with a low level of solar activity the $\mathrm{E}_{\mathrm{s}}$ layer response to the geomagnetic disturbances was more pronounced than during the years with a high level of solar activity.

While the widest variability in $f_{\mathrm{o}} E$ does occur at high values of solar activity (MSC of 80-100) the median change in critical frequency at all four hours does not appear to have any solar dependency.

\subsection{Testing for seasonal dependency}

The line, scatter and error bar plot in Fig. 2 captures the change in $f_{\mathrm{o}} E$ that occurs in each of the four hours following the SSC binned against the month in which the SSC occurred. The point joined by the solid line is the median value of all $\Delta f_{\mathrm{o}} E_{m-n}$ values that fall in the month. The error bars show the minimum and maximum values for each bin. Minimum and maximum values are again used in preference to the $25 \%$ and $75 \%$ quartiles in order to expose the magnitude of variability that can be expected.

The line, scatter and error bar plot polar plot in the top panel of Fig. 3 captures the change between $f_{\mathrm{o}} E$ measured across all four
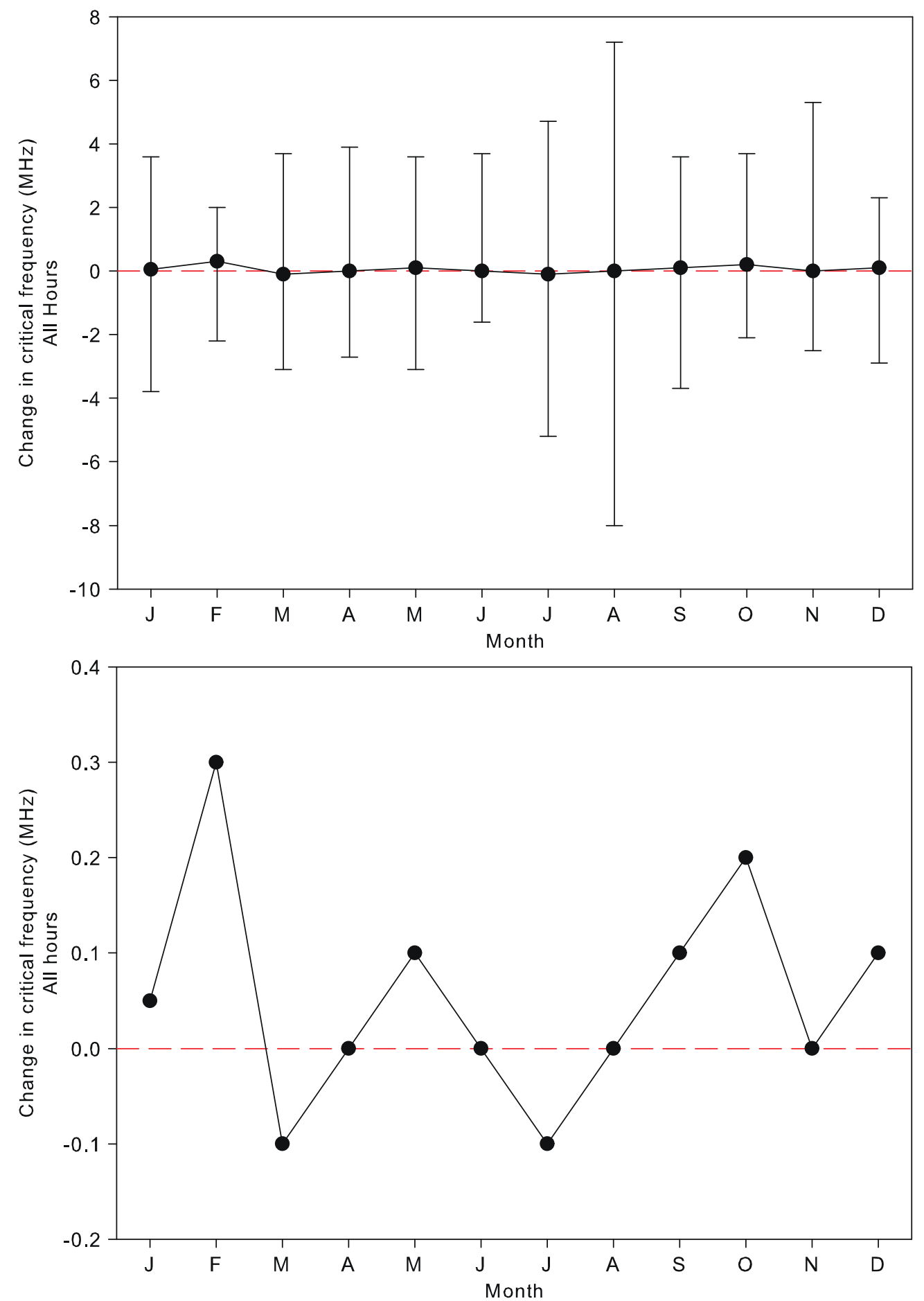

Fig. 3. Line, scatter and bar plots for four hours following SSC. The abscissa is month of measurement and the ordinate is $\Delta f_{\mathrm{o}} E_{m-n}$. 
hours following the SSC binned against the month in which the SSC occurred. The bottom panel in Fig. 3 has an expanded ordinate axis showing in fine detail the median variation in E-layer critical frequency.

During the first hour following an SSC there is a greater variability of $\Delta f_{\mathrm{o}} E$ in summer and autumn than in winter and spring (1st panel of Fig. 2). In the first and second hour (Fig. 2-1st and 2 nd panel) the median value of $f_{\mathrm{o}} E$ is elevated in winter but this is not the case in the third and fourth hour. Overall the variability of $\Delta f_{\mathrm{o}} E$ (top panel of Fig. 3) does not appear to have any seasonal dependency when viewed across all hours.

\subsection{The variability of $E_{s}$}

Extremely wide variations in ionospheric electron density profiles at auroral latitudes have been documented (Bates and
Hunsucker, 1974). Baron (1974) demonstrated the considerable variability of the E-region, in terms of electron density, between individual incoherent scatter radar scans only $20 \mathrm{~s}$ apart with ionisation extending down to relatively low altitudes of approximately $80-85 \mathrm{~km}$. Incidentally, this altitude information implies that the precipitating electrons that produced the ionisation were fairly energetic, having energies in the order of $20 \mathrm{keV}$.

This section examines, in some detail, the variability of $E_{s}$ in the four hours following an SSC and particular attention is given to the occurrence of screening. In order to accumulate an adequate number of samples the day was split into four sectors. Sector A covering the period 0-6 MLT, sector B covering 6-12 MLT, sector C covering 12-18 MLT and sector D covering 18-24 MLT. Polar plots are used in Fig. 4 where the radial axis is $\Delta f_{\mathrm{o}} E$ and the clock hours indicate magnetic local time. The solid dots indicate where full screening of the F-layers occurred. The associated line, scatter and error bar plot shows the median values of $\Delta f_{0} E_{m-n}$ per sector, the
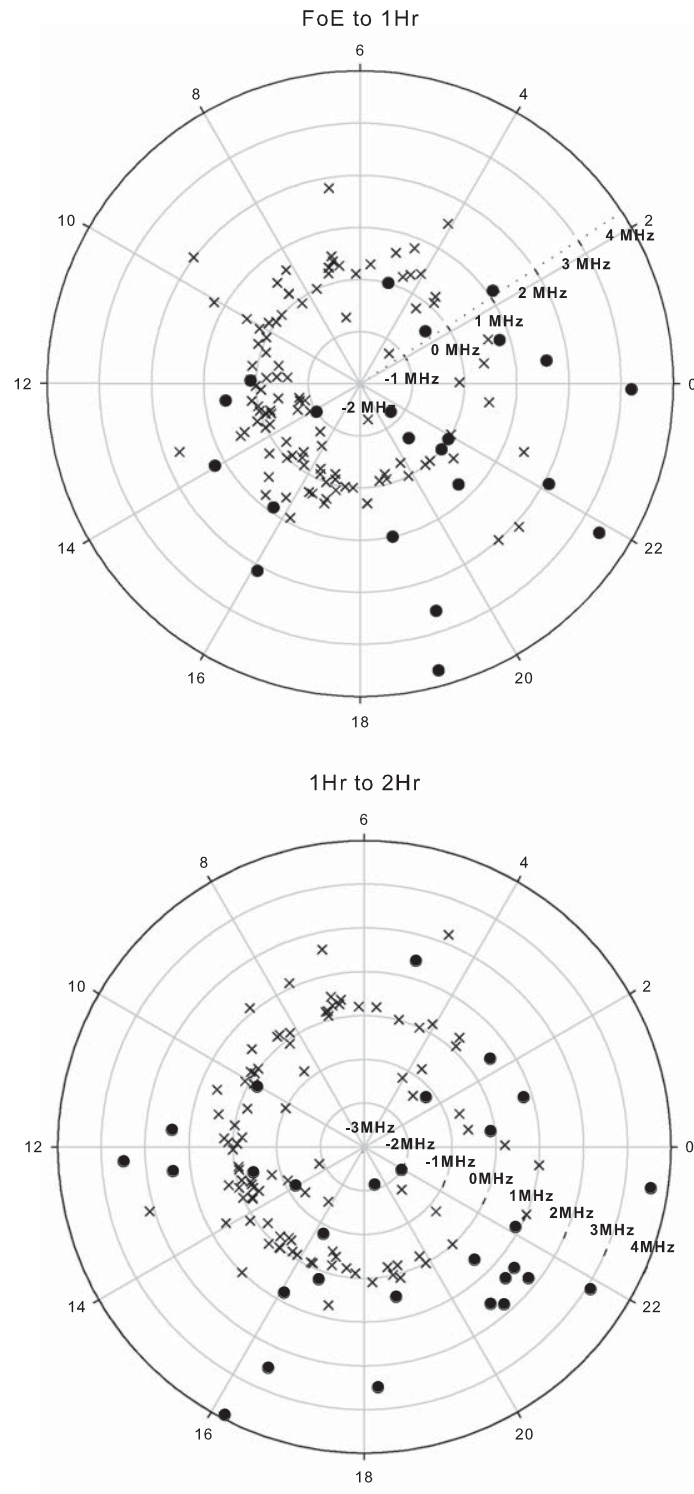
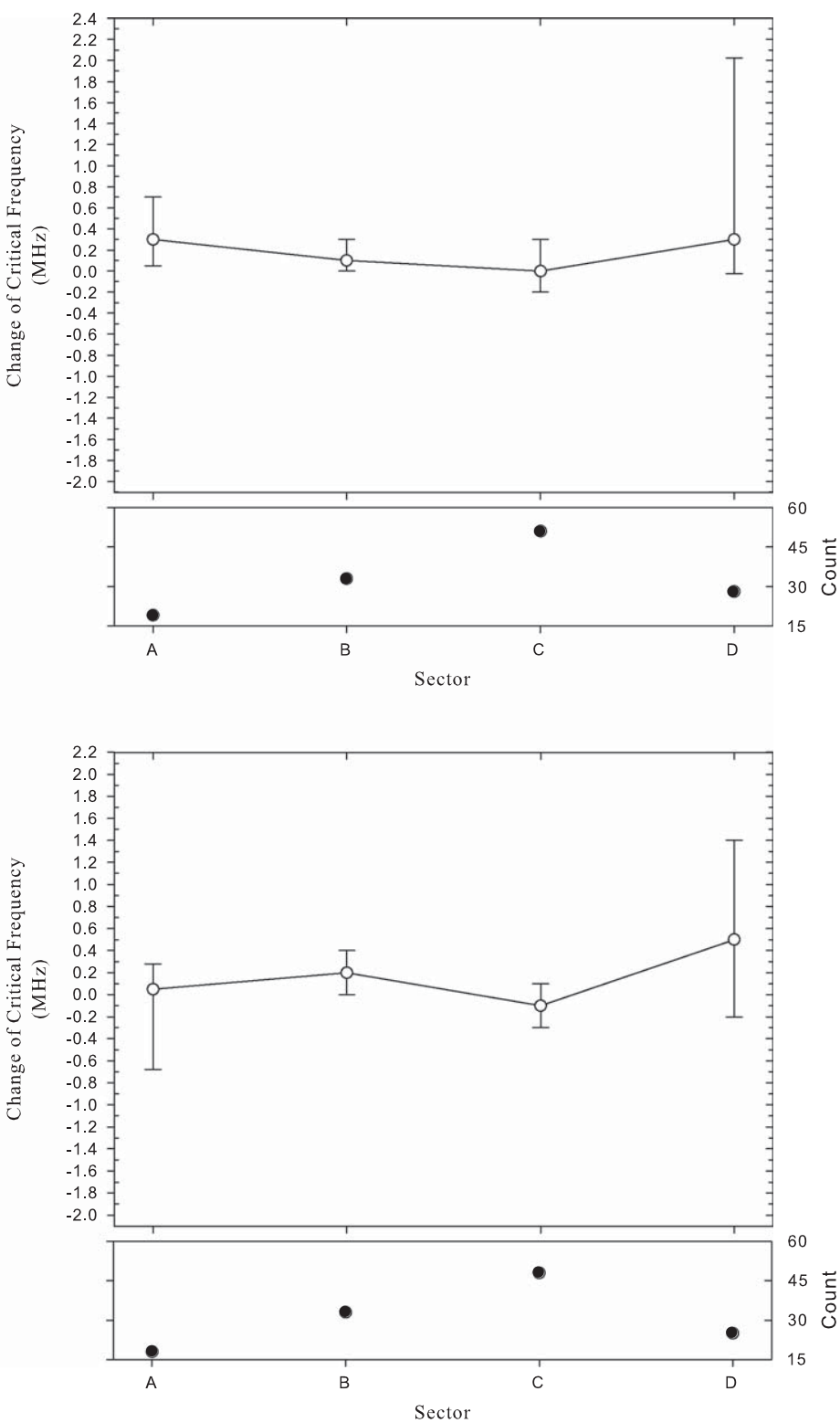

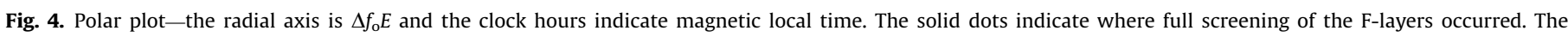

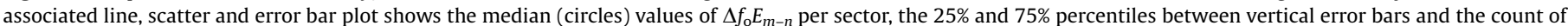
events in the lower panel. 

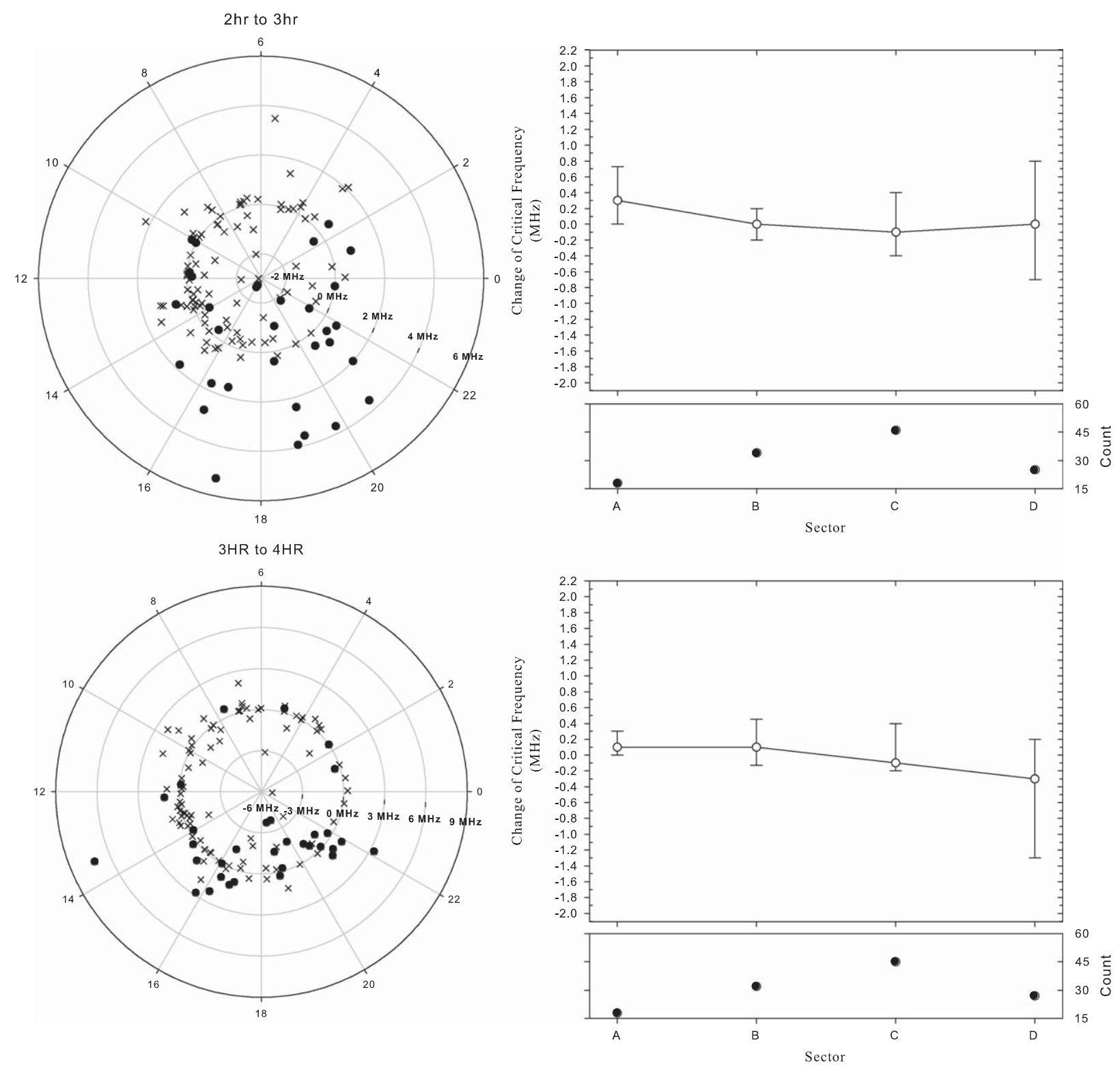

Fig. 4. (Continued)

$25 \%$ and $75 \%$ percentiles between vertical error bars and the count of events in the lower panel.

The statistics show considerable variation, as is expected when working with the ionosphere in general and which is amplified when dealing with the high latitude ionosphere. A number of significant points are noted from examining the panels of Fig. 4 . It is noted that $\Delta f_{\mathrm{o}} E_{0-1}$ can be positive or negative, which depends on whether or not storm-induced precipitation has commenced in this hour or not. Full blanketing (screening) can occur even when $\Delta f_{\mathrm{o}} E_{0-1}$ is negative. This implies that the F-layer ionisation has dramatically reduced; hence, even though the E-layer might be penetrated, no F-layer reflecting plane exists. Screening can occur when $\Delta f_{0} E_{0-1}$ is zero and this implies that F-layer ionisation is severely reduced or particle precipitation is maintaining a thick highly ionised $\mathrm{E}_{\mathrm{s}}$ layer.

In the first hour following SSC when $\Delta f_{\mathrm{o}} E_{0-1}$ exceeds $2.1 \mathrm{MHz}$ the onset of screening is guaranteed. Screening occurs in all sectors in the first hour $\left(\Delta f_{0} E_{0-1}\right)$ except between 6 and 12 MLT (sector B) where only one out of 33 events over a six-year period caused screening in the first hour. Screening occurs extensively in the second hour when $\Delta f_{\mathrm{o}} E_{1-2}$ exceeds $1 \mathrm{MHz}$ and exclusively when $\Delta f_{\mathrm{o}} E_{1-2}$ exceeds $2.1 \mathrm{MHz}$, identical to what occurs in the first hour $\left(\Delta f_{0} E_{0-1}\right)$.

In the third hour $\Delta f_{0} E_{2-3} \approx 2.1 \mathrm{MHz}$ continues to be a milestone indicator that guarantees screening will occur, with only one exception occurring in six years of data. The extensive occurrence of screening greatly increases in the third hour when $\Delta f_{\mathrm{o}} E_{2-3}$ exceeds $0.5 \mathrm{MHz}$, which is significantly less than in previous hours.

In the fourth hour $\Delta f_{\mathrm{o}} E_{3-4} \approx 3 \mathrm{MHz}$ is now a new milestone indicator that guarantees screening will occur. The extensive occurrence of screening at negative values of $\Delta f_{0} E_{3-4}$ in the fourth hour indicates that F-layer ionisation has dramatically reduced and that there is no F-layer reflecting plane even if the E-layer is penetrated. In this hour a $\Delta f_{\mathrm{o}} E_{3-4} \approx 2.1 \mathrm{MHz}$ again provides a good threshold with screening occurring exclusively in sectors $C$ and $D$ above this level.

Ring currents during magnetic storms move the auroral region (at the poleward boundary of the trapping region toward the equator) and all field lines from the auroral zone touch the outer 
boundary of the magnetosphere, thus allowing particle injection. This explains the highest $\Delta f_{\mathrm{o}} E_{m-n}$ values that occur in sector D (18-24 MLT) as sector D, is when the field lines are open to direct particle injection, directly opposite to sector B (6-12 MLT). Sectors $A$ and $C$ have similar statistics and variance reflecting their intermediate position between sectors $\mathrm{D}$ and $\mathrm{B}$.

\subsection{Likelihood of the occurrence of screening}

The histogram in Fig. 5 captures all $\Delta f_{\mathrm{o}} E_{m-n}$ data points binned against the hour (in MLT) in which the SSC occurred. Each bar covers all the data points that occur in each hour. The lower division of the bar (unshaded portion) shows the number of data points that did not screen the upper layers and the top division of each bar (shaded portion) shows the number of data points for which screening of the upper layers did occur. The scatter plot with dropped horizontal lines on the top of the histogram reflects the percentage blanketing that is represented by the division of each stacked bar.

The histogram shows a clear increase in blanketing events between 16:00 and 3:00 MLT, i.e. early evening, through midnight to the early morning hours. From 19 to 3 MLT there is a 50\% chance of screening to occur. This rises as high as $80 \%$ in the hour between 21 and 22 MLT. This reflects the local times at Sodankylä when the field lines are open to direct particle injection. The likelihood of screening between 3 and 14 MLT is below 20\% and increases in the hours up to 19 MLT.

\subsection{The threshold of screening}

Since the worldwide study undertaken by Smith (1957) the occurrence of $\mathrm{E}_{\mathrm{s}}$ has been linked to the value of $f_{\mathrm{o}} E$ exceeding $5 \mathrm{MHz}$ and since then this threshold has been used extensively in the literature when studying the long-term statistics of monthly median values.

Matsushita and Reddy (1967) examined the average daytime behaviour of mid-latitude blanketing $\mathrm{E}_{\mathrm{s}}$ on a worldwide basis, using $f_{\mathrm{b}} E_{\mathrm{s}}$ greater than $2 \mathrm{MHz}$. It must be noted that the blanketing referred to in this paper must not be confused with screening, which describes total blanketing. Blanketing $\left(f_{\mathrm{b}} E_{\mathrm{s}}\right)$ describes what is seen on an ionogram when the F-layer is only partially screened at lower frequencies-typically around $1.4-2.2 \mathrm{MHz}$. Screening describes what is seen on an ionogram when none of the F-layer can be discerned. This reflects the situation where no mitigation technique, e.g. reducing or increasing frequency or the modification of take-off angles, can achieve access to the F-layer.

Fig. 6 captures the median values of $f_{0} E_{\mathrm{s}}$ at which screening occurs in each sector across the six hours following SSC, i.e. the critical frequency of the E-layer at which screening of the F-layer occurs. The count of the number of screening events in each sector is shown in the lower panel. The fitted straight line provides an

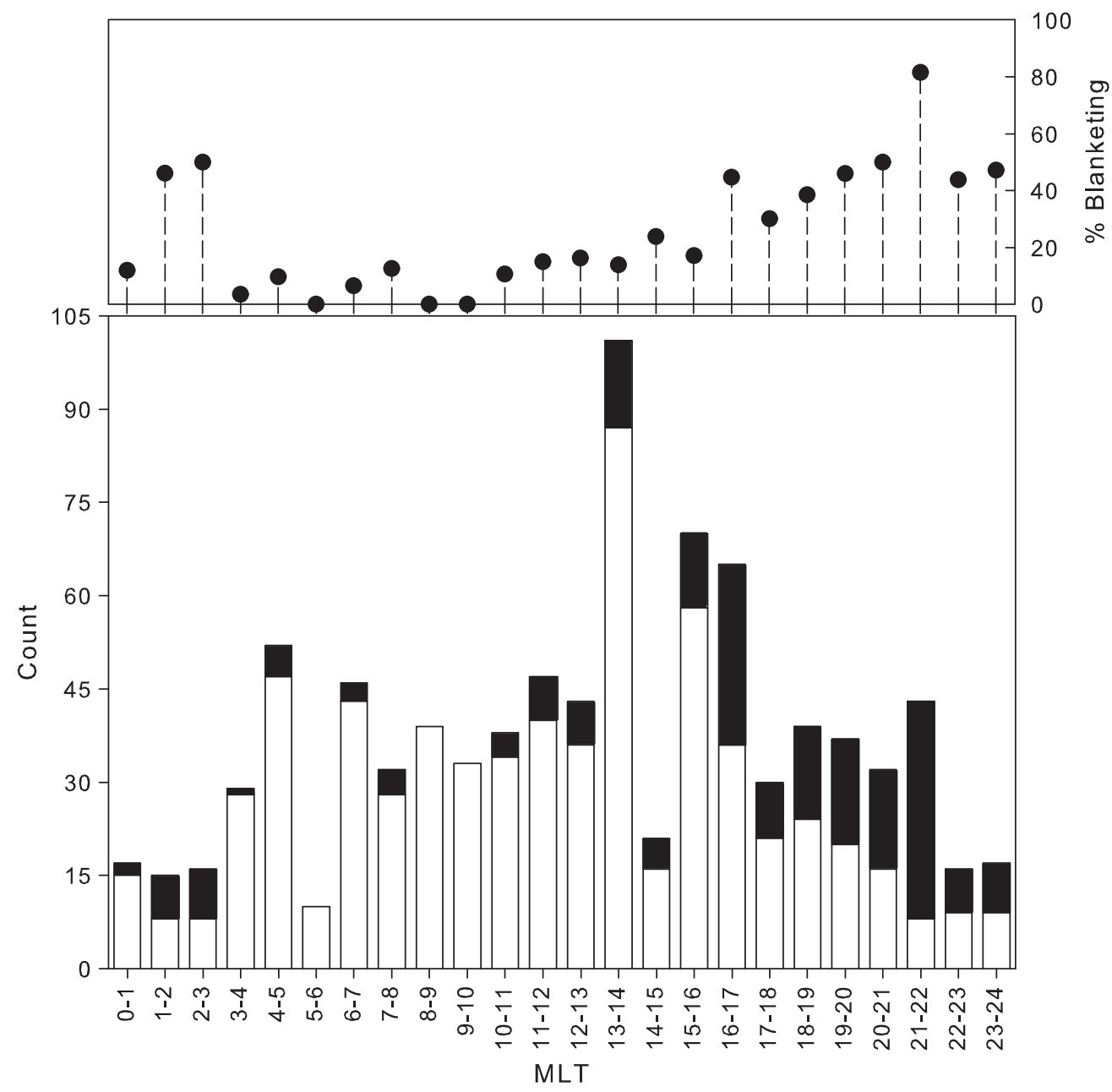

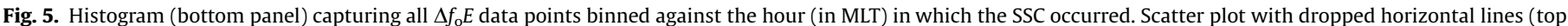
panel) reflects the percentage blanketing that is shown by the division of each histogram stacked bar. 


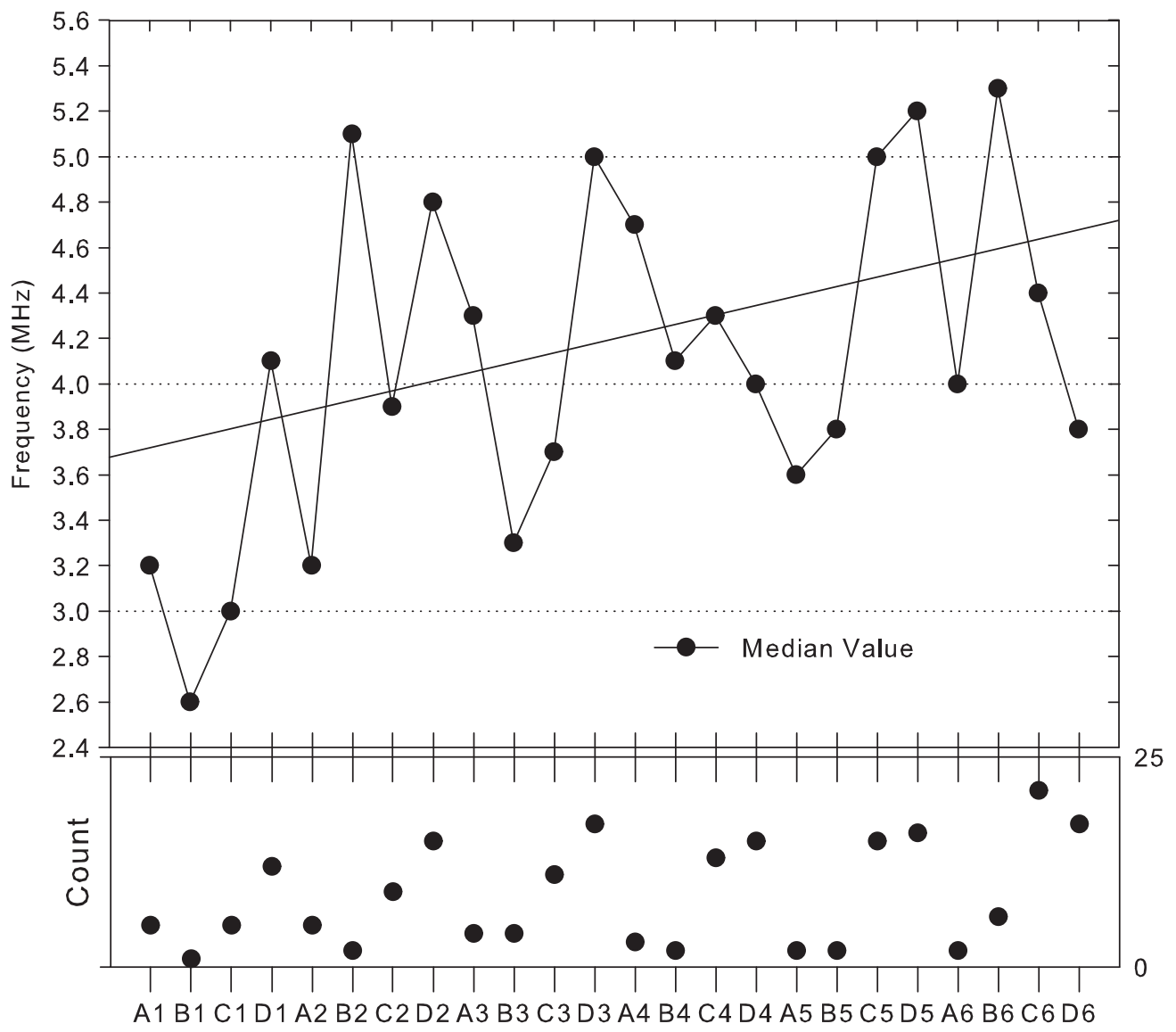

\section{Sector and Hour After SSC Occurs}

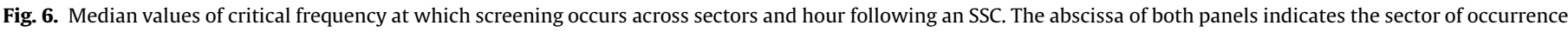

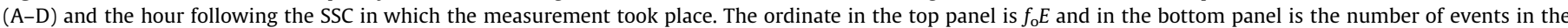
database for that sector.

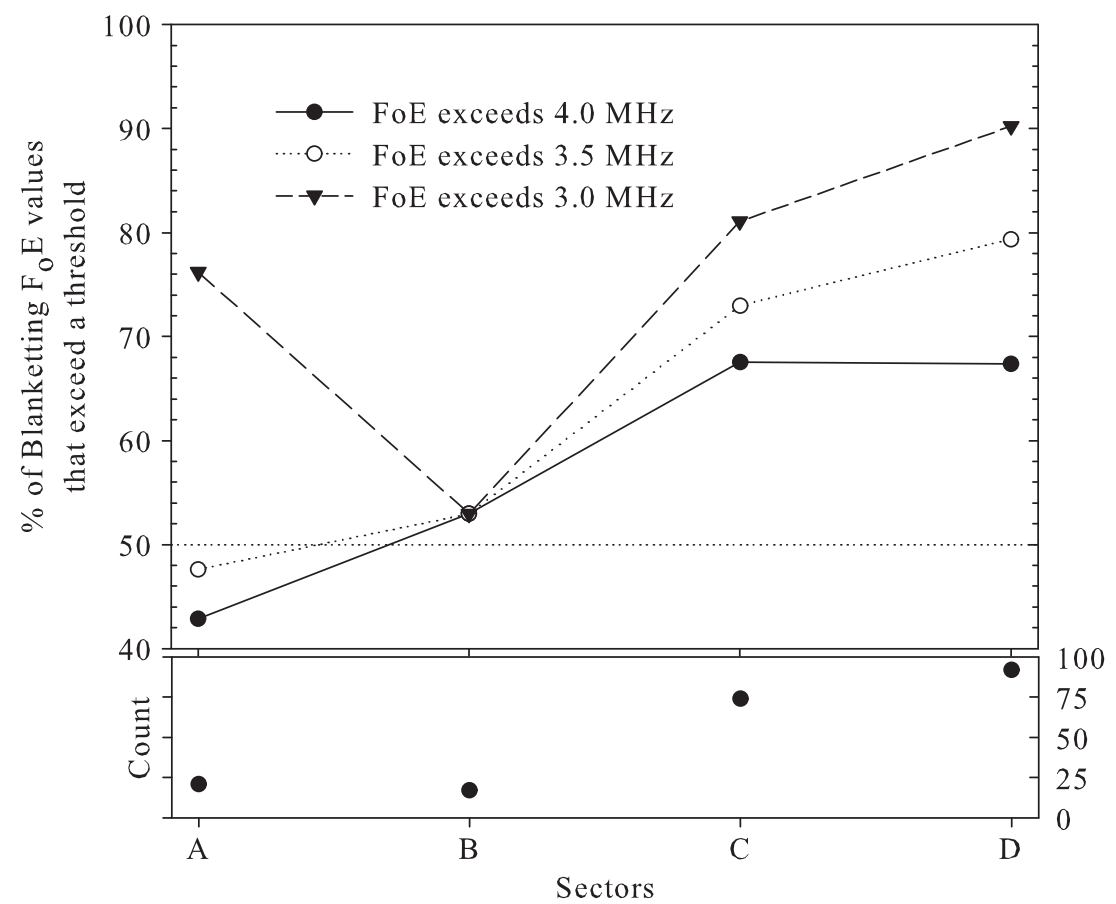

Fig. 7. Percentage of blanketing $f_{\mathrm{o}} E$ values exceeding set thresholds in each sector. 
indication of the increasing median value of critical frequency as we move away from the start of the disturbance, indicating the increase in E-layer ionisation as the storm progresses. The fitted straight line merely shows the increasing trend in median values. In the hour following SSC a critical E-layer frequency from 2.6 $\mathrm{MHz}$ upward can indicate that screening has occurred. Up to six hours after the SSC this value has increased to between 4 and $5 \mathrm{MHz}$ depending on sector.

It is clear from Fig. 6 that $f_{\mathrm{o}} E \geq 5 \mathrm{MHz}$ and $f_{\mathrm{o}} E \geq 2 \mathrm{MHz}$ are not appropriate values to indicate screening has occurred. Using $f_{\mathrm{o}} E \geq 5 \mathrm{MHz}$ would have resulted in missing the vast majority of blanketing events that occurred over the six-year period of this study. A value of $f_{\mathrm{o}} E \geq 2 \mathrm{MHz}$ is far too low and drastically overindicates the number of screening events. In establishing a typical value of screening, we must if possible take into account the influence that local time has on the value of screening $f_{\mathrm{o}} E$ as well as to account for the significant variation we see in the data.

Fig. 7 shows how important it is to include local time as well as the absolute value of $f_{0} E$ (not average or median values) with whatever screening threshold level is used. The ordinate axis in the top panel is the percentage of screening events that occurred which exceed three $f_{\mathrm{o}} E$ thresholds in each sector. The ordinate axis of the lower panel is the count of the number of events in the sixyear period of this study. The abscissa for both panels is the sector in which the SSC occurred. It must be mentioned that sectors A and B have the lowest occurrence of SSC and statistics are therefore based on a small sample of events in these two sectors.

Using $50 \%$ occurrence as a lower limit, a threshold of $4 \mathrm{MHz}$ (solid dots- ) is inadequate in sector A and barely adequate in sector B. A threshold of $3.5 \mathrm{MHz}$ (open dots-O) has similar inadequacies in sectors $A$ and $B$. A threshold of $3 \mathrm{MHz}$ (solid inverted triangles- $-\mathbf{v}$ ) is far more appropriate as a measure in all but sector $\mathrm{B}$. In sector $\mathrm{A}, 76 \%$ of blanketing $f_{\mathrm{o}} E$ exceeds $3 \mathrm{MHz}$; this falls in sector B to $53 \%$, rising to $82 \%$ in sector C and to $90 \%$ in sector D.

While the proposed threshold of $f_{\mathrm{o}} E_{\mathrm{s}} \geq 3 \mathrm{MHz}$ lacks accuracy in sector $\mathrm{B}$, it is a value of E-layer critical frequency that favourably indicates screening of the ionospheric layers above the E-layer in the hours following an SSC.

\section{Conclusions}

$E_{s}$ has different characteristics in different latitudinal zones and there may be several mechanisms governing the behaviour of these layers. The high latitude $E_{s}$ layers are generally considered to be due to particle precipitation (Buchau et al., 1972; Whitehead, 1970; Whalen et al., 1971; Wagner et al., 1973). Naridner et al. (1980) found that electron precipitation usually is the major cause for the formation of the high latitude Sporadic-E layer and that the modified wind shear mechanism, which takes into account the effect of electric fields, is important under low electron precipitation conditions only.

$\mathrm{E}_{\mathrm{s}}$ layers are important to consider at high latitudes where they are almost always present and frequently of sufficient ionisation to totally reflect radio waves in the $3-10 \mathrm{MHz}$ range at vertical incidence. There are also occasions when total blanketing occurs, i.e., periods when the layers above the E-layer are completely screened off. When this occurs the mode of propagation for a short-range HF link is limited to a one or two hop $\mathrm{E}_{\mathrm{s}}$ path, even at frequencies far greater than $10 \mathrm{MHz}$ which would normally penetrate the E-layer.

This paper details the deviation of $f_{\mathrm{o}} E_{\mathrm{s}}$ (from its quietionosphere value) for the four hours immediately following the SSC and establishes a threshold of deviation that predicts the onset of fully blanketing $E_{s}$ in the four hours following an
SSC. The methodology of using the occurrence of SSC as the starting point of each investigation ensures a well defined and understood starting point from which to gather data and examine the magnitude and variance of expected disturbances to the Elayer. While the proposed threshold of screening, $f_{\mathrm{s}} E_{\mathrm{s}} \geq 3 \mathrm{MHz}$, lacks accuracy in sector B (6-12 MLT) when there are very few occurrences of screening, it is a value of E-layer critical frequency which favourably indicates screening of the ionospheric layers above the E-layer in the four hours following an SSC.

It is seen from Fig. 4 that following the SSC the critical frequency of the $E_{s}$ layer increases above the norm. This will adversely affect the operation of HF radio-communication systems used at high latitudes unless corrective action is taken as these $E_{s}$ modes have different frequency/ground range dependencies from the $F_{2}$ mode. This phenomenon known as "E-layer cut off" (Davies, 1965) is significant in high latitude regions because any frequency that penetrates the $E_{s}$ layer at a given point to reach the F-layer is also close to the maximum useable frequency (MUF) of the $\mathrm{F}_{2}$-layer at its point of incidence with that layer. Partially reflecting $\mathrm{E}_{\mathrm{s}}$ can cause serious multipath and mode interference, especially detrimental to data transmission systems.

A second compelling reason for unreliable $F_{2}$ mode propagation at high latitude is the possibility of complete blockage (or screening) of the F-layer by $E_{s}$ as shown in Fig. 5. Such an enhanced layer of $E_{s}$ would augment the power in a signal propagated at a frequency below the E-layer MUF. For example, a highly ionised patch of $E_{s}$ may make $F_{2}$-layer propagation impossible but may also contribute to a low-loss reflection point on an E mode propagation path thus enhancing that mode's signal quality.

While these characteristics can be helpful or harmful to radio communications, either type of $\mathrm{E}_{\mathrm{s}}$ (i.e., partially blanketing and full blanketing) may extend the useful frequency range and its presence can be effectively used in system design and operations if it is understood (Lane, 2001). Of course for the $E_{s}$ mode path to be successfully used, the antenna at both the receiver and transmitter must have a suitable radiation pattern with sufficient gain to take advantage of the different range of transmission angles required to achieve the same ground range as an F-layer using an $\mathrm{E}_{\mathrm{s}}$ layer reflection path.

Following an SSC event or during magnetic storms, one rational approach toward using the ionosphere for HF communications in high latitude regions is to rely solely on E-layer modes, i.e. to fully utilise the enhanced E-layer. From an operational point of view a technique is needed to address the uncertainties generated by ionospheric disturbances on key ionospheric parameters and a number of authors have proposed, for example, the use of oblique and vertical sounding data to provide near real-time ionospheric maps and communication performance parameters (e.g., Zolesi et al., 2004; Goodman and Ballard, 1999). Certainly while each of these approaches has different applications and merits, the authors have chosen another approach. The use of propagation prediction programs to establish, in advance, the choice of operating frequency is still the basis of many operations and is good enough for operational purposes during quiet conditions. The problem to be overcome is to determine what propagation parameters need to be modified during disturbed conditions, i.e., what consequential modifications need to be made to the communications system to ensure some form of continued operation during disturbed conditions.

This investigation into disturbances affecting the E-region has led to the characterisation of the change in the value of the critical frequency of $E_{s}$ and the occurrence of fully blanketing $E_{s}$ following an SSC. The strength of this approach is that system operators can adjust for the deviation of critical frequencies from the quietionosphere predictive norm following SSC and the onset of storms, 
without the need for a supporting network of vertical and/or oblique sounders.

\section{Acknowledgments}

This research is supported by the author's employer, the Commission for Communications Regulation (ComReg), Dublin, Ireland.

We acknowledge the University of Oulu, Sodankylä Geophysical Observatory for the use of their f-plots.

\section{References}

Baggaley, W.J., 1984. Ionosphere sporadic-E parameters: long term trends. Science 225 (4664), 830-833.

Baron, M.J., 1974. Electron densities within aurora and other auroral E-region characteristics. Radio Science 9 (2), 341-348.

Bates, H.F., Hunsucker, R.D., 1974. Quiet and disturbed electron density profiles in the auroral zone ionosphere. Radio Science 9 (4), 455-467.

Batista, I.S., Paula, E.R., Abdu, M.A., Trivedi, N.B., 1991. Ionospheric effects of the March 13, 1989, magnetic storm at low and equatorial latitudes. Journal of Geophysical Research 96 (13), 13943-13952.

Blagoveshchensky, D.V., Borisova, T.D., 2000. Substorm effects of ionosphere and HF propagation. Radio Science 35 (5), 1165-1171.

Buchau, J., Gasman, G.J., Pike, C.P., Wagner, R.A., Whalen, J.A., 1972. Precipitation patterns in the Arctic ionosphere determined from airborne observations. Annales de Geophysique 28, 443-453.

Buonsanto, M.J., 1999. Ionospheric storms-a review. Space Science Reviews 88, 563-601.

Burlaga, L.F., Ogilvie, K.W., 1969. Causes of sudden commencements and sudden impulses. Journal of Geophysical Research 74 (11), 2815-2825.

Collis, P.N., Haggstrom, I., 1991. High latitude ionospheric response to a geomagnetic sudden commencement. Journal of Atmospheric and Terrestrial Physics 53 (3/4), 241-248.

Damatie, B., Nygrén, T., Lehtinen, M.S., Huuskonen, A., 2002. High resolution observations of sporadic-E layers within the polar cap ionosphere using a new incoherent scatter radar experiment. Annales Geophysicae 20,1429-1438.

Davies, K., 1990. Ionospheric Radio. Peter Peregrinus Press, London (IEE Electromagnetic Waves Series 31).

Davies, K., 1965. Ionospheric radio propagation. NBS Monograph 80, 165-192 (Chapter 4).

Ebro Observatory, 2009. Web page of the International Service on Rapid Magnetic Variations. Accessed on the 25 April 2009, 〈http://www.obsebre.es/php/ geomagnetisme/variaciorap.php $>$.

Friedrich, M., 2002. Data coverage for D-region modeling. In: Proceedings of the XXVIIth General Assembly of the International Union of Radio Science, Maastricht, The Netherlands, 17-24 August, pp. 2282-2285.

Goodman, J.M., Ballard, J.W., 1999. Dynamic management of HF communication and broadcasting systems. In: IEE Colloquium on Frequency Selection and Management Techniques for HF Communications, 18/1-18/05.

Gosling, J.T., Asbridge, J.R., Bame, S.J., Hundhausen, A.J., Strong, I.B., 1967. Discontinuities in the solar wind associated with sudden geomagnetic impulses and storm commencements. Journal of Geophysical Research 72, 3357-3363.

Hargreaves, J.K., 1992. The Solar-Terrestrial Environment. Cambridge University Press, Cambridge, UK.

Herman, J.R., Penndorf, R.B., 1963. Reception of mid-latitude transmissions in northern Canada. In: Landmark, B. (Ed.), Arctic Communications. AGARDograph, vol. 78, pp. 97-119.

Hinteregger, H.E., Hall, L.A., Schmidtke, G., 1965. Solar XUV radiation and neutral particle distribution in July 1963 thermosphere. In: Space Research, vol. 5. North-Holland Publishing Company, Amsterdam, pp. 1175-1190.

Hirshberg, J., Alksne, A., Colburn, D.S., Bame, S.J., Hundhausen, A.J., 1970. Observation of a solar flare induced interplanetary shock and helium-enriched driver gas. Journal of Geophysical Research 75 (1), 1-15

King, G.A.M., 1962. The night E layer. In: Smith, E.K., Matsushita, S. (Eds.), Ionospheric Sporadic E. Pergamon Press, New York, pp. 219-231.

Kirkwood, S., Nilsson, H., 2000. High latitude sporadic-E and other thin layers-the role of magnetospheric electric fields. Space Science Reviews 91, 579-613.

Lane, G., 2001. Signal-to-Noise Predictions using VOACAP, Including VOAAREA-A Users Guide, Rockwell Collins, 523-0780552-10111R.
Majeed, T., 1982. Comparison of percentage occurrence of $E_{s}$ in Karachi and Islamabad under magnetic conditions. Indian Journal of Radio and Space Physics 11 (3), 120-130.

Maksyutin, S.V., Fahrutdinova, A.N., Sherstyukov, O.N., 2001. Es layer and dynamics of neutral atmosphere during the periods of geomagnetic disturbances. Journa of Atmospheric and Solar-Terrestrial Physics 63, 545-549.

Mathews, J.D., 1998. Sporadic E: current views and recent progress. Journal of Atmospheric and Solar-Terrestrial Physics 60 (4), 413-435.

Matsushita, S., Reddy, C.A., 1967. A study of blanketing Sporadic-E at middle latitudes. Journal of Geophysical Research 72 (11), 2903-2916.

McNamara, L.F., 1991. The Ionosphere: Communications, Surveillance and Direc tion Finding. Krieger Publishing Company, Florida.

Morton, Y.T., Mathews, J.D., 1993. Effects of the 13-14 March 1989 geomagnetic storm on the E-region tidal ion layer structure at Arecibo during AIDA. Journal of Atmospheric and Terrestrial Physics 55, 467-485.

Naridner, N., Steen Mikkelsen, I., Stockflet Jørgensen, T., 1980. On the formation of high latitude $\mathrm{E}_{\mathrm{s}}$ layers. Journal of Atmospheric and Terrestrial Physics 42, $841-852$.

Nygréen, T., Jalonen, L., Oksman, J., Turunen, T., 1984. The role of electric field and neutral wind direction in the formation of sporadic $\mathrm{E}$ layers. Journal of Atmospheric and Terrestrial Physics 46, 373-381.

Ogilvie, K.W., Burlage, L.F., Wilkerson, T.D., 1968. Plasma observations on explorer 34. Journal of Geophysical Research 73 (21), 6809-6824.

Parkinson, M.L., Dyson, P.L., Monselesan, D.P., Morris, R.J., 1998. On the role of electric field direction in the formation of sporadic E-layers in the southern polar cap ionosphere. Journal of Atmospheric and Solar-Terrestrial Physics 60, 471-491.

Paul, A.K., 1985. F-region tilts and ionogram analysis. Radio Science 20 (4), 959-971.

Piggott, W.R., Rawer, R., 1972. URSI Handbook of ionogram interpretation and reduction. Second ed., Report UAG-23, World Data Centre A for Solar Terrestrial Physics. NOAA, Boulder, Colorado.

Rastogi, R.G., Pathan, B.M., Rao, D.R.K., Sastry, T.S., Sastri, J.H., 2001. On latitudinal profile of storm sudden commencement in $\mathrm{H}, \mathrm{Y}$ and $\mathrm{Z}$ at Indian Geomagnetic Observatory chain. Earth, Planets and Space 53,121-127.

Smith, E.K., 1957. World-Wide Occurrence of Sporadic E, Circular 582. National Institute of Standards and Technology, Gaithersburg, Md.

Smith, E.K., 1962. The occurrence of sporadic E. In: Smith, E.K., Matsushita, S. (Eds.), Ionospheric Sporadic E. Pergamon Press, New York, pp. 3-12.

Takeuchi, T., Russell, C.T., Araki, T., 2002. Effect of the orientation on interplanetary shock on the geomagnetic sudden commencement. Journal of Geophysical Research 107 (A12), 1423-1432.

Tamao, T., 1975. Unsteady interactions of solar wind disturbances with the magnetosphere. Journal of Geophysical Research 80 (31), 4230-4236.

Tamao, T., 1964. The structure of three-dimensional hydromagnetic waves in uniform cold plasma. Journal of Geomagnetism and Geoelectricity (Japan) 16, 89-114.

Tsurutani, B.T., Gonzalez, W.D., Gonzalez, A.L.C., Tang, F., Okada, J.K., 1995 Interplanetary origin of geomagnetic activity in the declining phase of the solar cycle. Journal of Geophysical Research 100 (A11), 21717-21734.

Wagner, R.A., Snyder, A.L., Akasofu, S.-I., 1973. The structure of the polar ionosphere during exceptionally quiet periods. Planetary and Space Science 21 (11) 1911-1916.

Wan, W., Parkinson, M.L., Dyson, P.L., Breed, A.M., Morris, R.J.A., 1999. A statistical study of the interplanetary magnetic field control of sporadic E-layer occurrence in the southern polar cap ionosphere. Journal of Atmospheric and Solar-Terrestrial Physics 61 (18), 1357-1366.

Whalen, J.A., Buchau, J., Wagner, R.A., 1971. Airborne ionospheric and optica measurements of noontime aurora. Journal of Atmospheric and Terrestrial Physics 33 (4), 661-678.

Whitehead, J.D., 1961. The formation of sporadic-E layer in temperate zones. Journal of Atmospheric and Terrestrial Physics 20, 49-58.

Whitehead, J.D., 1989. Recent work on mid-latitude and equatorial sporadic E. Journal of Atmospheric and Solar-Terrestrial Physics 51 (5), 401-424.

Whitehead, J.D., 1970. Production and prediction of sporadic E. Reviews of Geophysics and Space Physics 8 (1), 65-144.

Wilken, B., Goertz, C.K., Baker, D.N., Higbie, P.R., Fritz, T.A., 1982. The SSC on July 29 1977 and its propagation within the magnetosphere. Journal of Geophysical Research 87 (A8), 5901-5910.

Wilken, B., Baker, D.N., Higbie, P.R., Fritz, T.A., Olsen, W.P., Pfitzer, K.A., 1986 Magnetospheric configuration and energetic particle effects associated with SSC: a case study of the CDAW 6 event on March 22, 1979. Journal of Geophysical Research 91 (A2), 1459-1473.

Zolesi, B., Belehaki, A., Tsagouri, I., Cander, L.R., 2004. Real-time updating of the simplified ionospheric regional model for operational applications. Radio Science 39 (2) 